\title{
SUBCUTANEOUS ANTERIOR TRANSPOSITION FOR TREATMENT OF CUBITAL TUNNEL SYNDROME: IS THIS METHOD SAFE AND EFFECTIVE?
}

Sara Lima', João Freitas Correia', Rui Moura Martins' ${ }^{1}$, Jorge Miguel Alves², João Palheiras², Carlos de Sousa ${ }^{3}$

\section{ABSTRACT}

Objective: To evaluate the results from subcutaneous anterior transposition of the cubital nerve for treating cubital tunnel syndrome (CTS) and the influence of prognostic factors such as preoperative McGowan stage, age and duration of symptoms. Methods: 36 patients with CTS who underwent subcutaneous anterior transposition of the cubital nerve between 2006 and 2009 were evaluated after an average follow-up of 28 months. Their mean age was 41.6 years. Nine patients were in McGowan stage I, 18 in stage II and nine in stage III. Results: There was a statistically significant improvement in sensory and motor deficits. $78 \%$ of the patients with severe neuropathy improved after surgery. According to the modified Bishop score, 21 patients $(58.3 \%)$ had excellent results, seven (19.4\%) good, six $(16.7 \%)$ satisfactory and two $(5.55 \%)$ poor. The satisfaction rate was $86 \%$ and $72 \%$ of the patients recovered their daily activities without limitations. Conclusion: The severity of neuropathy and preoperative duration of symptoms, but not age, had a negative influence on the outcome. The subcutaneous anterior transposition of the cubital nerve is safe and effective for treating CTS of different degrees of severity. Given the major prognostic factors identified, surgical treatment should be advised as soon as axonal loss has become clinically evident.

Keywords - Ulnar Nerve; Cubital Tunnel Syndrome; Prognostic

\section{INTRODUCTION}

The ulnar nerve can be compressed to varying degrees in its path along the upper limb, with the elbow being the most frequent localization. The resulting neuropathy, known as the cubital tunnel syndrome (CTS) is the second most frequent upper limb neuropathy after carpal tunnel syndrome ${ }^{(1)}$.

Its etiology includes metabolic disorders, congenital anomalies, sequelae of elbow trauma, osteoarthritis, and chronic valgus stress, among others. It is idiopathic in $10-30 \%$ of cases.

Patients often present with paresthesias in the territory of ulnar nerve distribution and weakness or atrophy of the intrinsic muscles of the hand. The extent of ulnar nerve dysfunction was stratified by McGowan into three grades ${ }^{(2)}$ : grade I, sensory changes alone; grade II, muscle weakness; grade III, paresis and muscle atrophy.
The current treatment for patients with significant pain symptoms or paresthesia in the ulnar nerve territory, or weakness with atrophy of intrinsic hand muscles due to the compression of the ulnar nerve at the elbow is surgical decompression ${ }^{(3)}$. However, there is still no consensus on the ideal surgical technique for the treatment of CTS. Several techniques have been described over the years, including simple decompression ${ }^{(4)}$, anterior transposition (subcutaneous, intramuscular, or submuscular) ${ }^{(5-7)}$, medial epicondylectomy ${ }^{(8-10)}$ and in situ endoscopic decompression ${ }^{(11-13)}$.

The aim of this study was to evaluate the outcome of subcutaneous anterior transposition of the ulnar nerve in the treatment of CTS and whether the recovery is influenced by factors such as the preoperative McGowan grade, age, and duration of symptoms.

1 - Complementary Intern, Tâmega and Sousa Hospital Center, Penafiel, Portugal.

2 - Hospital Assistant, Tâmega and Sousa Hospital Center, Penafiel, Portugal.

3 - Clinic Head/Clinic Director, Tâmega and Sousa Hospital Center, Penafiel, Portugal.

Study conducted at the Tâmega and Sousa Hospital Center, Penafiel, Portugal.

Correspondence: Rua Teixeira de Pascoaes, 219, 5 H, 4460-431 - Senhora da Hora, Portugal. Email: saralimaraujo@gmail.com

Received for publication: 1/29/2012, accepted for publication: 4/12/2012.

The authors declare that there was no conflict of interest in conducting this work 


\section{METHODS}

We conducted a retrospective study that included all patients who underwent subcutaneous anterior transposition of the ulnar nerve at the Tâmega and Sousa Hospital Center, Portugal, between 2006 and 2009. The CTS diagnosis was based on clinical history of paresthesia/hypoaesthesia in the area of ulnar nerve distribution, intrinsic hand muscle weakness or atrophy, in conjunction with a nerve conduction velocity of the ulnar nerve less than $50 \mathrm{~m} / \mathrm{s}$ through the elbow. Exclusion criteria included a follow-up period of less than 12 months, surgery for recurrence of CTS, severe neurological or musculoskeletal pathology in the ipsilateral upper limb, except for other associated compressive neuropathies.

Thirty-six patients met the selection criteria, including 17 men and 19 women. The mean age was 41.6 years (23-72 years) and in 22 cases the operated side was the dominant side. A specific etiology could not be identified in 27 cases $(75 \%)$, which were classified as idiopathic. Seven cases were attributed to the sequelae of elbow trauma with valgus deformity greater than or equal to $20^{\circ}$, and two to osteoarthritis of the elbow. The professional activity was distributed as follows: 22 were manual laborers (seven of whom worked continuously resting on their elbows), three were office workers, one was unemployed, and 10 were retired.

The mean preoperative duration of symptoms was 14.6 months (3-48 months). All patients had intermittent or persistent paresthesias and/ or hypoaesthesias in the territory of ulnar nerve distribution (Table 1). The Tinel test at the cubital tunnel was positive in $94 \%$ of patients and elbow flexion produced paresthesias in the ulnar nerve territory in 69\%. Twenty-six patients showed some degree of motor deficit, ranging from mild, moderate, and severe, according to the presence of diagnostic signs, including atrophy of the first interosseous dorsal and hypothenar muscles, claw-finger in the

Table 1 - Sensory deficits pre- and postoperatively.

\begin{tabular}{c|c|c}
\hline Sensory deficits & Preop & Postop \\
\hline Absent & - & 16 \\
\hline Intermittent & 16 & 17 \\
\hline Persistent & 20 & 3 \\
\hline
\end{tabular}

fifth finger, inability to cross the second and third fingers, positive Froment test, and Wartenberg sign, according to the distribution shown in Table 2. The muscle strength of the intrinsic muscles of the hand and the deep flexor of the fifth finger, according to the Medical Research Council scale (0-5) was 3.5 and 4.1, respectively. The extent of ulnar nerve dysfunction, stratified according to the McGowan classification, made it possible to classify nine patients as grade I, 18 patients as grade II, and nine as grade III.

In all patients in this study it was not possible to obtain symptomatic relief with conservative treatment such as activity modification, use of nonsteroidal antiinflammatory drugs or nighttime immobilization in elbow extension.

Table 2 - Motor deficits pre- and postoperatively.

\begin{tabular}{c|c|c|c}
\hline $\begin{array}{c}\text { Pre- and postoperative frequence of physical } \\
\text { signs indicating motor deficits }\end{array}$ & Preop & Postop \\
\hline Severe & $\begin{array}{c}\text { Severe atrophy + claw-finger on the fifth } \\
\text { finger + inability to cross the second } \\
\text { and third fingers + positive Froment + } \\
\text { positive Wartenberg }\end{array}$ & 9 & 2 \\
\hline Moderate & $\begin{array}{c}\text { Moderate atrophy + inability to cross } \\
\text { the second and third fingers + positive } \\
\text { Froment + positive Wartenberg }\end{array}$ & 10 & 7 \\
\hline Mild & Mild atrophy + absence of positive signs & 7 & 2 \\
\hline Absent & No atrophy & 10 & 25 \\
\hline
\end{tabular}

\section{Surgical technique}

Under general or locoregional anesthesia, a medial incision is performed from 12 to $15 \mathrm{~cm}$ in line with the posterior condylar groove. Bearing in mind the preservation of the branches of the medial antebrachial cutaneous nerve, and after dividing the fascia, the nerve is identified at the medial epicondyle, immediately proximal to its entry into the cubital tunnel. Aponeurotic thickening between the medial epicondyle and olecranon (Osborne fascia) is split, freeing the nerve from the cubital tunnel.

The release is continued distally as the nerve passes between the two heads of the FCU until we are certain that there are no points of distal compression. Likewise, the nerve is followed proximally along the medial head of the triceps about 7 to 8 $\mathrm{cm}$, with the division of the intermuscular septum and the Struthers' arcade. Once it is completely de- 
compressed, the nerve is dissected from its bed in the ulnar groove and transposed to a position anterior to the medial epicondyle, with attention given to preserving its branches to the ulnar carpal flexor and flexor digitorum profundus. Potential points of residual compression or exaggerated angulation are excluded. A portion of subcutaneous tissue is sutured to the fascia over the medial epicondyle to prevent the nerve from returning to its anatomical position. No postoperative immobilization is performed.

\section{Clinical evaluation}

Patients were examined at a mean time of 27.7 months (12-51 months) after surgery. Patient reports of symptoms of paresthesias and/or hypoaesthesias were recorded, as well as all clinical parameters considered preoperatively and complications resulting from surgery. Functional capacity was evaluated according to the functional scale of the American Shoulder and Elbow Society (Table 3), wherein the value of 100 corresponds to normal function. The end result was based on the modified Bishop scale (Table 4), thus classified as excellent, good, satisfactory, or poor. Patients were also asked about their satisfaction with the outcome of surgery.

Tabela 3 - Escala de função da Sociedade Americana do Ombro e Cotovelo.

Circle the number that indicates your ability to do the following activities

\begin{tabular}{l|c|c|c|c}
\hline \multicolumn{1}{c|}{ Activity } & \multicolumn{4}{c}{ Score } \\
\hline 1. Do Up Top Button on Shirt & 0 & 1 & 2 & 3 \\
\hline 2. Manage Toileting & 0 & 1 & 2 & 3 \\
\hline 3. Comb Hair & 0 & 1 & 2 & 3 \\
\hline 4. Tie Shoes & 0 & 1 & 2 & 3 \\
\hline 5. Eat with Utensils & 0 & 1 & 2 & 3 \\
\hline 6. Carry a Heavy Object & 0 & 1 & 2 & 3 \\
\hline 7. Rise from Chair Pushing with Arms & 0 & 1 & 2 & 3 \\
\hline 8. Do Heavy Household Chores & 0 & 1 & 2 & 3 \\
\hline 9. Turn a Key & 0 & 1 & 2 & 3 \\
\hline 10. Throw a Ball & 0 & 1 & 2 & 3 \\
\hline 0 unable to do; 1= very difficult to do: 2= somewhat difficult: $3=$ not difficult.
\end{tabular}

$0=$ unable to do; $1=$ very difficult to do; $2=$ somewhat difficult; $3=$ not difficult.

Rev Bras Ortop. 2012;47(6):748-53
Table 4 - Modified Bishop scale.

\begin{tabular}{|c|c|}
\hline & Points \\
\hline \multicolumn{2}{|l|}{ Satisfaction } \\
\hline Satisfied & 2 \\
\hline Satisfied with reservation & 1 \\
\hline Dissatisfied & 0 \\
\hline \multicolumn{2}{|l|}{ Improvement } \\
\hline Better & 2 \\
\hline Unchanged & 1 \\
\hline Worse & 0 \\
\hline
\end{tabular}

Severity of residual symptoms (pain, paresthesia, dysesthesia, weakness, clumsiness)

\begin{tabular}{l|c}
\hline Asymptomatic & 3 \\
\hline Mild, occasional & 2 \\
\hline Moderate & 1 \\
\hline Severe & 0 \\
\hline
\end{tabular}

Work status

\begin{tabular}{l|l}
\hline Working or able to work at previous job & 1 \\
\hline Not working because of ulnar neuropathy & 0 \\
\hline Leisure activity & 1 \\
\hline Unlimited & 0 \\
\hline Limited & \\
\hline
\end{tabular}

Strength

\begin{tabular}{l|l}
\hline Intrinsic muscle strength normal (M5) & 2 \\
\hline Intrinsic muscle strength reduced to M4 & 1 \\
\hline Intrinsic muscle strength less than equal to M3 & 0 \\
\hline
\end{tabular}

Sensibility (static two-point discrimination)

\begin{tabular}{l|c}
\hline Normal $(\leq 6 \mathrm{~mm})$ & 1 \\
\hline Abnormal $(>6 \mathrm{~mm})$ & 0 \\
\hline Total & 12 \\
\hline
\end{tabular}

\section{Statistical analysis}

Statistical analysis was performed using SPSS 18. The Mann-Whitney and Kruskal-Wallis tests were used to compare continuous variables and the chi-square and Fisher's exact tests were used for categorical variables. Differences were considered statistically significant if the $\mathrm{p}$ value was less than 0.05 . 


\section{RESULTS}

Subjectively, $78 \%$ of patients improved after surgery and $36 \%$ had total remission of sensory deficits (Table 1). Fifty-three percent had a positive Tinel test and $11 \%$ had a positive elbow flexion test. There was an improvement in motor deficits in $61 \%$ of patients and only two patients maintained a severe deficit (Table 2). In the postoperative evaluation, the average strength of the intrinsic hand muscles was 4.5 and 4.8 for the deep flexor of the fifth finger. The improvement in motor and sensory deficits was statistically significant $(\mathrm{p}=0.02)$.

There was a statistically significant improvement in the McGowan grade $(\mathrm{p}<0.001)$. Thirty-six percent had a complete postoperative recovery of symptoms and a normal physical examination and were classified as grade 0 , and $78 \%$ of patients with severe neuropathy improved after surgery. Although 75\% were classified preoperatively as grade II and III, after surgery, $72 \%$ of patients had a normal motor function (Figure 1).

With the technique used, the satisfaction rate was $86 \%$. Of the six unsatisfied patients, all of whom were manual laborers, four had persistent symptoms and two experienced their recurrence after a period of remission. The two patients with recurrence of symptoms become symptomatic again between three and six months after surgery, and both were associated with prolonged symptoms, the concomitant presence of other compressive neuropathies and were involved in lawsuits. All patients who did not experience improvements were McGowan grade III and had a history of surgery for carpal tunnel syndrome, two of whom had symptoms with more than a year of evolution - one retired and other received compensation.

According to the modified Bishop scale, we obtained 21 (58.3\%) excellent, seven (19.4\%) good, six (16.7\%) satisfactory, and two poor results $(5.55 \%)$ (Figure 2). The functional scale score improved from a mean of 56.2 (SD 21.92) to 83 (SD 17.51), which was statistically significant $(\mathrm{p}<0.001)$, and $72 \%$ of cases recovered daily activities without limitations.

As complications, we had five cases of pain at the scar, four cases of paresthesias in the elbow, and one early superficial infection.

The duration of symptoms and the preoperative McGowan grade were associated with postoperative recovery: patients operated up to 12 months and those

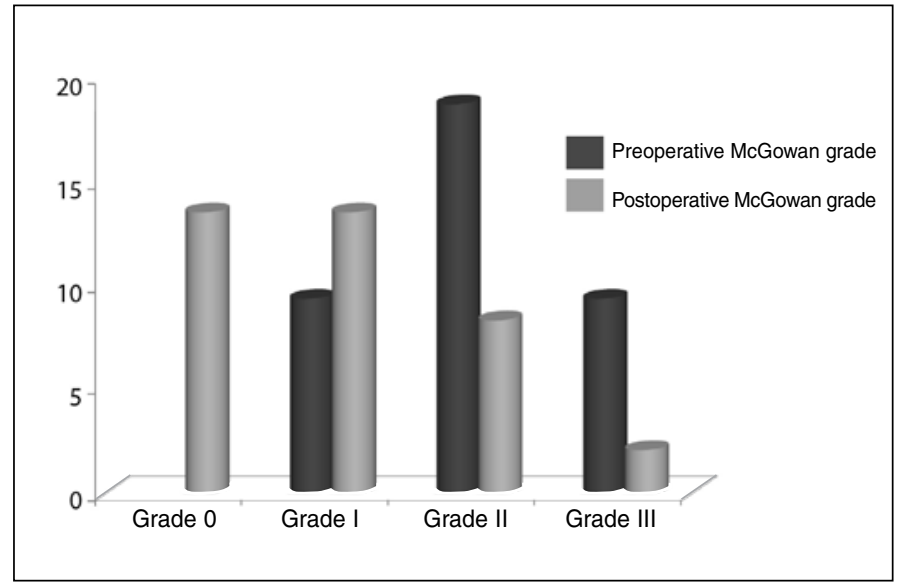

Figure 1 - McGowan grade distribution pre and postoperatively.

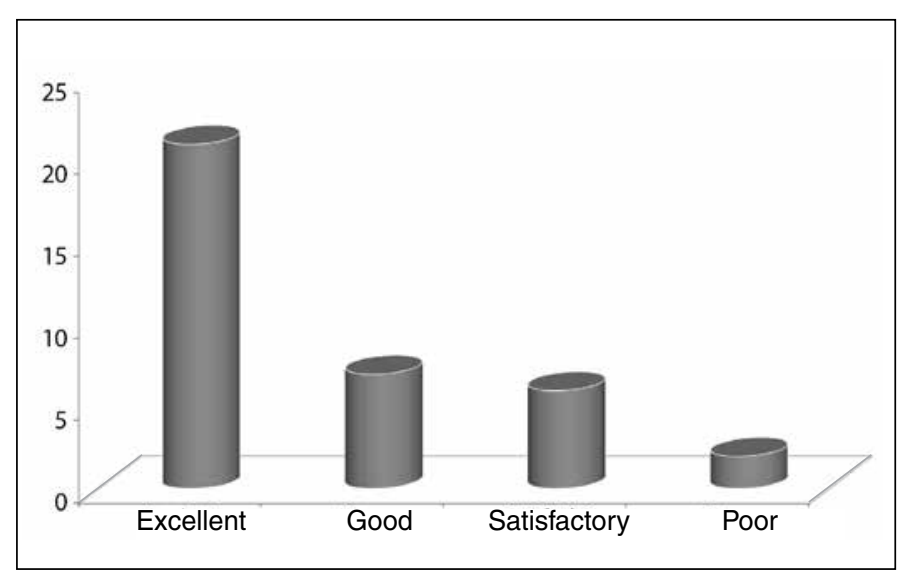

Figure 2 - Modified Bishop scale results.

with a McGowan grade of I or II had better recovery according to the modified Bishop scale and a higher rate of satisfaction.

\section{DISCUSSION}

There are multiple surgical techniques currently recommended for the treatment of $\mathrm{CTS}^{(4-13)}$, though considerable controversy remains in the literature regarding the best surgical strategy for this compressive neuropathy. Most comparative studies demonstrate similar results and no particular technique has been demonstrated to be associated with statistical differences among the results obtained ${ }^{(14-23)}$.

In the absence of an anatomic lesion, proponents of simple decompression argue that the ulnar nerve transposition involves an unnecessary extensive dissection and the risk of nerve injury or devascularization. In turn, proponents of anterior transposition consider that dynamic compression of the nerve with elbow flexion $^{(24,25)}$ can only be properly resolved by this 
technique. Subcutaneous transposition has the advantages of being less invasive, less technically demanding, and allowing for early postoperative mobilization ${ }^{(26)}$ when compared with intramuscular or submuscular transposition of the ulnar nerve; however, it places the nerve in a position vulnerable to repetitive trauma, particularly in thin patients.

The largest meta-analyses conducted to date ${ }^{(19,20)}$, comparing simple decompression with anterior transposition of the ulnar nerve, found no statistically significant differences between the two methods. However, Macadam et $\mathrm{al}^{(20)}$ found there to be a trend towards a better clinical outcome in patients treated with anterior transposition as opposed to simple decompression, requiring additional randomized prospective studies that use objective measures to provide statistical support for this finding. Similar to what has been published in the literature ${ }^{(5,14,21,27)}$, we found high rates of success and satisfaction with subcutaneous transposition.

Several studies have shown the influence of factors such as the duration and severity of preoperative symptoms in the sensory and motor recovery of these patients $^{(18,23,24,28,29)}$. Advanced age has also been suggested by some authors as a predictor ${ }^{(18,29)}$. In this study, the severity of neuropathy and duration of preoperative symptoms ( $>12$ months) had a negative influence on the final result. However, we found no association between advanced age and outcome. The relatively young age of our population may have been involved as a factor, but additional studies are needed to evaluate the prognostic value of this parameter in the postoperative recovery. The rate of postoperative complications was relatively low and comparable to other studies. With the technique used, it is important to bear in mind the need to preserve the posterior branch of the medial antebrachial cutaneous nerve to avoid changes in the sensitivity of the elbow and forearm, painful scars or neuromas.

The main limitations of this study include the fact that this was a retrospective study with a relatively small sample; the use of subjective measures rather than objective, instrumented, and standardized measurements that would be able to give more rigor to the study; the treatment was performed by multiple surgeons; the inclusion of patients with other associated compressive neuropathies, a consequence of their high prevalence in the study population.

\section{CONCLUSION}

Subcutaneous anterior transposition of the ulnar nerve is a safe and effective technique for the treatment of its compression at the elbow, in addition to being a simple technique and that is performed relatively quickly. The duration and severity of preoperative symptoms are the main prognostic factors and significantly influence the postoperative recovery of these patients. Therefore, surgical treatment should be advised as soon as axonal injury becomes clinically evident and patients with prolonged symptoms should be cautioned about the possibility of not obtaining a complete clinical recovery.

\section{REFERENCES}

1. Robertson C, Saratsiotis J. A review of compressive ulnar neuropathy at the elbow. J Manipulative Physiol Ther. 2005;28(5):345.

2. McGowan AJ. The results of transposition of the ulnar nerve for traumatic ulnar neuritis. J Bone Joint Surg Br. 1950 ;32(3):293-301.

3. Elhassan B, Steinmann SP. Entrapment neuropathy of the ulnar nerve. J Am Acad Orthop Surg. 2007;15(11):672-81.

4. Huang JH, Samadani $U$, Zager EL. Ulnar nerve entrapment neuropathy at the elbow: simple decompression. Neurosurgery. 2004;55(5):1150-3.

5. Caputo A, Song WJ. Subcutaneous transposition of the ulnar nerve in the athletic elbow. Techn Orthop.. 2006;21:325-30.

6. Kleinman WB, Bishop AT. Anterior intramuscular transposition of the ulnar nerve. J Hand Surg Am. 1989;14(6):972-9.

7. Dellon AL. Techniques for successful management of ulnar nerve entrapment at the elbow. Neurosurg Clin N Am. 1991;2(1):57-73.

8. Popa M, Dubert T. Treatment of cubital tunnel syndrome by frontal partial medial epicondylectomy. A retrospective series of 55 cases. J Hand Surg Br. 2004;29(6):563-7.

9. Osterman AL, Spiess AM. Medial epicondylectomy. Hand Clin. 2007;23(3):329-37.

10. Viveiros MEM, Matsumoto MH, Bastos TB, Moraes MJS, Uehara A, Pereira $H$. Treatment of cubital tunnel syndrome using the technique of medial partial epicondylectomy of the elbow. Rev Bras Ortop. 2008;43(11-12):490-6.

11. Porcellini G, Paladini P, Campi F, Merolla G. Arthroscopic neurolysis of the ulnar nerve at the elbow. Chir Organi Mov. 2005;90(2):191-200.

12. Hoffmann $R$, Siemionow M. The endoscopic management of cubital tunnel syndrome. J Hand Surg Br. 2006;31(1):23-9.

13. Ahcan $U$, Zorman $P$. Endoscopic decompression of the ulnar nerve at the elbow. J Hand Surg Am. 2007;32(8):1171-6.

14. Bartels RH, Verhagen WI, van der Wilt GJ, Meulstee J, van Rossum LG, Grotenhuis JA. Prospective randomized controlled study comparing simple decompression versus anterior subcutaneous transposition for idiopathic neuropathy of the ulnar nerve at the elbow: Part 1. Neurosurgery. 2005;56(3):522-30.

15. Biggs $M$, Curtis JA. Randomized, prospective study comparing ulnar neurolysis in situ with submuscular transposition. Neurosurgery. 2006;58(2):296-304.

16. Gervasio O, Gambardella G, Zaccone C, Branca D. Simple decompression versus anterior submuscular transposition of the ulnar nerve in severe cubital tunnel syndrome: a prospective randomized study. Neurosurgery. 2005;56(1):108-17.

Rev Bras Ortop. 2012;47(6):748-53 
17. Keiner D, Gaab MR, Schroeder HW, Oertel J. Comparison of the long-term results of anterior transposition of the ulnar nerve or simple decompression in the treatment of cubital tunnel syndrome--a prospective study. Acta Neurochir (Wien). 2009;151(4):311-5.

18. Charles YP, Coulet B, Rouzaud JC, Daures JP, Chammas M. Comparative clinical outcomes of submuscular and subcutaneous transposition of the ulnar nerve for cubital tunnel syndrome. J Hand Surg Am. 2009;34(5):866-74.

19. Zlowodzki M, Chan S, Bhandari M, Kalliainen L, Schubert W. Anterior transposition compared with simple decompression for treatment of cubital tunnel syndrome. A meta-analysis of randomized, controlled trials. J Bone Joint Surg Am. 2007;89(12):2591-8.

20. Macadam SA, Gandhi R, Bezuhly M, Lefaivre KA. Simple decompression versus anterior subcutaneous and submuscular transposition of the ulnar nerve for cubital tunnel syndrome: a meta-analysis. J Hand Surg Am. 2008;33(8):1314.e1-12.

21. Baek GH, Kwon BC, Chung MS. Comparative study between minimal medial epicondylectomy and anterior subcutaneous transposition of the ulnar nerve for cubital tunnel syndrome. J Shoulder Elbow Surg. 2006;15(5):609-13.

22. Nabhan A, Ahlhelm F, Kelm J, Reith W, Schwerdtfeger K, Steudel WI. Simple decompression or subcutaneous anterior transposition of the ulnar nerve for cubital tunnel syndrome. J Hand Surg Br. 2005;30(5):521-4.
23. Watts AC, Bain GI. Patient-rated outcome of ulnar nerve decompression: a comparison of endoscopic and open in situ decompression. J Hand Surg Am. 2009;34(8):1492-8.

24. Iba K, Wada T, Aoki M, Tsuji H, Oda T, Yamashita T. Intraoperative measurement of pressure adjacent to the ulnar nerve in patients with cubital tunnel syndrome. J Hand Surg Am. 2006;31(4):553-8.

25. Gelberman RH, Yamaguchi K, Hollstien SB, Winn SS, Heidenreich FP $\mathrm{Jr}$, Bindra RR, et al. Changes in interstitial pressure and cross-sectional area of the cubital tunnel and of the ulnar nerve with flexion of the elbow. An experimental study in human cadavera. J Bone Joint Surg Am. 1998;80(4):492-501.

26. Black BT, Barron OA, Townsend PF, Glickel SZ, Eaton RG. Stabilized subcutaneous ulnar nerve transposition with immediate range of motion. Long-term follow-up. J Bone Joint Surg Am. 2000;82(11):1544-51.

27. Lascar T, Laulan J. Cubital tunnel syndrome: a retrospective review of 53 anterior subcutaneous transpositions. J Hand Surg Br. 2000;25(5):453-6.

28. Mowlavi A, Andrews K, Lille S, Verhulst S, Zook EG, Milner S. The management of cubital tunnel syndrome: a meta-analysis of clinical studies. Plast Reconstr Surg. 2000;106(2):327-34.

29. Yamamoto K, Shishido T, Masaoka T, Katori Y, Tanaka S. Postoperative clinical results in cubital tunnel syndrome. Orthopedics. 2006;29(4):347-53. 